\title{
Mineralization-defects are comparable in fluorotic impacted human teeth and fluorotic mouse incisors
}

Citation for published version (APA):

Jalali, R., Ghazanfari, S., Guy, F., Lyaruu, D., van Ruijve, L., DenBesten, P., Martignon, S., Castiblanco, G., \& Bronckers, A. (2017). Mineralization-defects are comparable in fluorotic impacted human teeth and fluorotic mouse incisors. Archives of Oral Biology, 83, 214-221.

https://doi.org/10.1016/j.archoralbio.2017.07.018

Document status and date:

Published: 01/11/2017

DOI:

10.1016/j.archoralbio.2017.07.018

Document Version:

Publisher's PDF, also known as Version of record

Document license:

Taverne

Please check the document version of this publication:

- A submitted manuscript is the version of the article upon submission and before peer-review. There can be important differences between the submitted version and the official published version of record.

People interested in the research are advised to contact the author for the final version of the publication, or visit the DOI to the publisher's website.

- The final author version and the galley proof are versions of the publication after peer review.

- The final published version features the final layout of the paper including the volume, issue and page numbers.

Link to publication

\footnotetext{
General rights rights.

- You may freely distribute the URL identifying the publication in the public portal. please follow below link for the End User Agreement:

www.umlib.nl/taverne-license

Take down policy

If you believe that this document breaches copyright please contact us at:

repository@maastrichtuniversity.nl

providing details and we will investigate your claim.
}

Copyright and moral rights for the publications made accessible in the public portal are retained by the authors and/or other copyright owners and it is a condition of accessing publications that users recognise and abide by the legal requirements associated with these

- Users may download and print one copy of any publication from the public portal for the purpose of private study or research.

- You may not further distribute the material or use it for any profit-making activity or commercial gain

If the publication is distributed under the terms of Article $25 \mathrm{fa}$ of the Dutch Copyright Act, indicated by the "Taverne" license above, 
Research paper

\title{
Mineralization-defects are comparable in fluorotic impacted human teeth and fluorotic mouse incisors
}

\author{
Rozita Jalali $^{\mathrm{a}, *}$, Franck Guy ${ }^{\mathrm{b}, 1}$, Samaneh Ghazanfari ${ }^{\mathrm{c}, 1}$, Don Lyaruu ${ }^{\mathrm{a}}$, Leo van Ruijven ${ }^{\mathrm{a}}$, \\ Pamela DenBesten $^{\mathrm{d}}$, Stefania Martignon ${ }^{\mathrm{e}}$, Gina Castiblanco ${ }^{\mathrm{e}}$, Antonius L.J.J. Bronckers ${ }^{\mathrm{a}}$

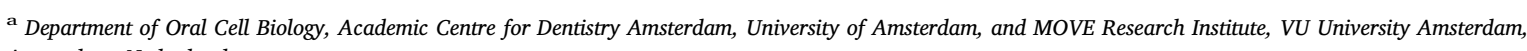 \\ Amsterdam, Netherlands \\ b CNRS INEE UMR 7262 - IPHEP, Institut de Paléoprimatologie et Paléontologie Humaine, Evolution et Paléoenvironnements, Université de Poitiers - Faculté des Sciences, \\ Poitiers, Cedex 9, France \\ ${ }^{\mathrm{c}}$ Department of Orthopaedic Surgery - VU Medical Centre, MOVE Research Institute Amsterdam, Amsterdam, Netherlands and the Aachen-Maastricht Institute for \\ Biobased Materials, Faculty of Humanities and Sciences, Maastricht University, Maastricht, Netherlands \\ d Department of Orofacial Sciences, School of Dentistry, University of California, San Francisco, CA, 94143-0422, USA \\ e UNICA - Caries Research Unit, Research Vice-rectory, Universidad El Bosque, Bogotá, Colombia
}

\section{A R T I C L E I N F O}

\section{Keywords:}

Hypomineralization

Dental fluorosis

Enamel development

Hypermineralization

\begin{abstract}
A B S T R A C T
Objective: Fluoride excess of $0.05-0.07 \mathrm{mg} \mathrm{F} / \mathrm{kg}$ bw/day in water or food additives like salt is the principal cause of endemic dental fluorosis. How fluoride causes these defects is not clear yet. Recent studies in rodents suggest that development of enamel fluorosis is associated with insufficient neutralization of protons released during the formation of hypermineralized lines.

Design: Here we examined whether hypermineralization could also be assessed by MicroCT in developing molar enamel of humans exposed to fluoride.

Result: Micro-CT analysis of hypomineralized enamel from human fluorotic molars graded by the Thylstrup-Fejerskov (TF) Index as III-IV showed weak hypermineralized lines and hypermineralized patches not seen in TF-I/II grade enamel. The mesio-distal sides of these molar teeth were significantly smaller $(\sim 18 \%$, $\mathrm{p}=0.02$ ) than in TF-I/II teeth.

Conclusion: The patterns of changes observed in human fluorotic teeth were similar to those in fluorotic rodent incisors. The data are consistent with the hypothesis that also in developing human teeth fluoride-stimulated local acidification of enamel could be a mechanism for developing fluorotic enamel.
\end{abstract}

\section{Introduction}

Dental fluorosis is the hypomineralization of dental enamel caused by chronic ingestion of fluoride during the formative stages of the dental hard tissue (Fejerskov, Larsen, Richards, \& Baelum, 1994). The severity of the condition depends on the time, dose and duration of fluoride intake (Fejerskov et al., 1994). Clinically, human enamel fluorosis ranges from mild (containing more accentuated perikymata) to more severe fluorosis when the teeth develop white opacities. Most severe changes seen when teeth have erupted are extensive enamel pitting and partial loss of enamel, presumably formed after eruption (Thylstrup \& Fejerskov, 1978). To investigate the mechanisms of fluorosis many studies (Angmar-Månsson \& Whitford, 1984; DenBesten, 1986; DenBesten et al., 2002; Lyaruu et al., 2014) made use of experimental animals mostly rodents. Important is also that rodents develop enamel fluorosis at the same plasma $\mathrm{F}$ levels as in human (Angmar-Månsson, Ericsson, \& Ekberg, 1977; Everett et al., 2002).

Ameloblasts produce tooth enamel in a two-step process. During the secretory stage, ameloblasts secrete an organic matrix mostly consisting of amelogenins. At the end of this stage, the enamel layer achieves its full thickness. Moderate-to-high exposure of rodents to fluoride especially at the beginning of secretory stage - can influence the ameloblast structure, enamel matrix mineralization and the thickness of the enamel layer (Kierdorf \& Kierdorf, 1997; Monsour, Harbrow, \& Warshawsky, 1989; Smith, Nanci, \& DenBesten, 1993; Walton \& Eisenmann, 1974). During secretion stage but most by maturation stage amelogenins are degraded by proteases such as MMP20 (secretion stage) and KLK4 (maturation stage), while enamel continues

\footnotetext{
* Corresponding author at: Department of Oral Cell Biology, ACTA, Gustav Mahlerlaan 3004, Amsterdam, Netherlands.

E-mail address: r.jalali@acta.nl (R. Jalali).

${ }^{1}$ These authors have contributed equally to this work.
} 

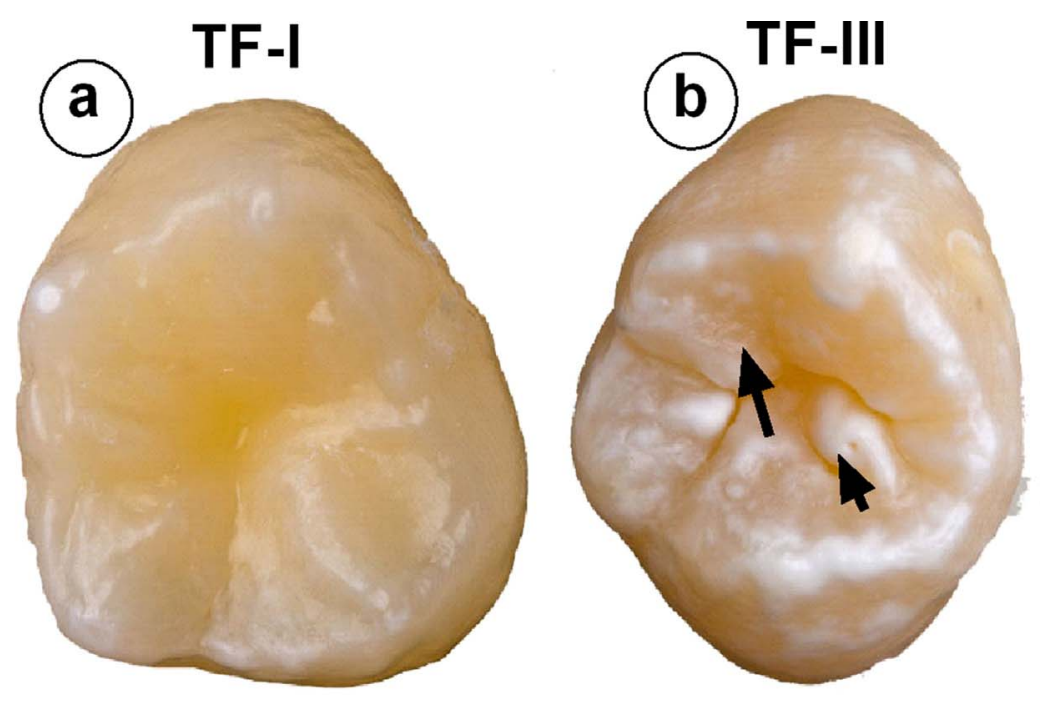

Fig. 1. Enamel surface defects in response to fluoride measured by QLF. (a, b) Occlusal view of bright light image of molars with white spots in non-plaque retention areas (black arrows in (b)). (c, d) QLF image showing less mineralized areas (red arrows in (d)). (e) Shows the summary of QLF measurements ( $\mathrm{n}=6$ for each group). (For interpretation of the references to color in this figure legend, the reader is referred to the web version of this article.)
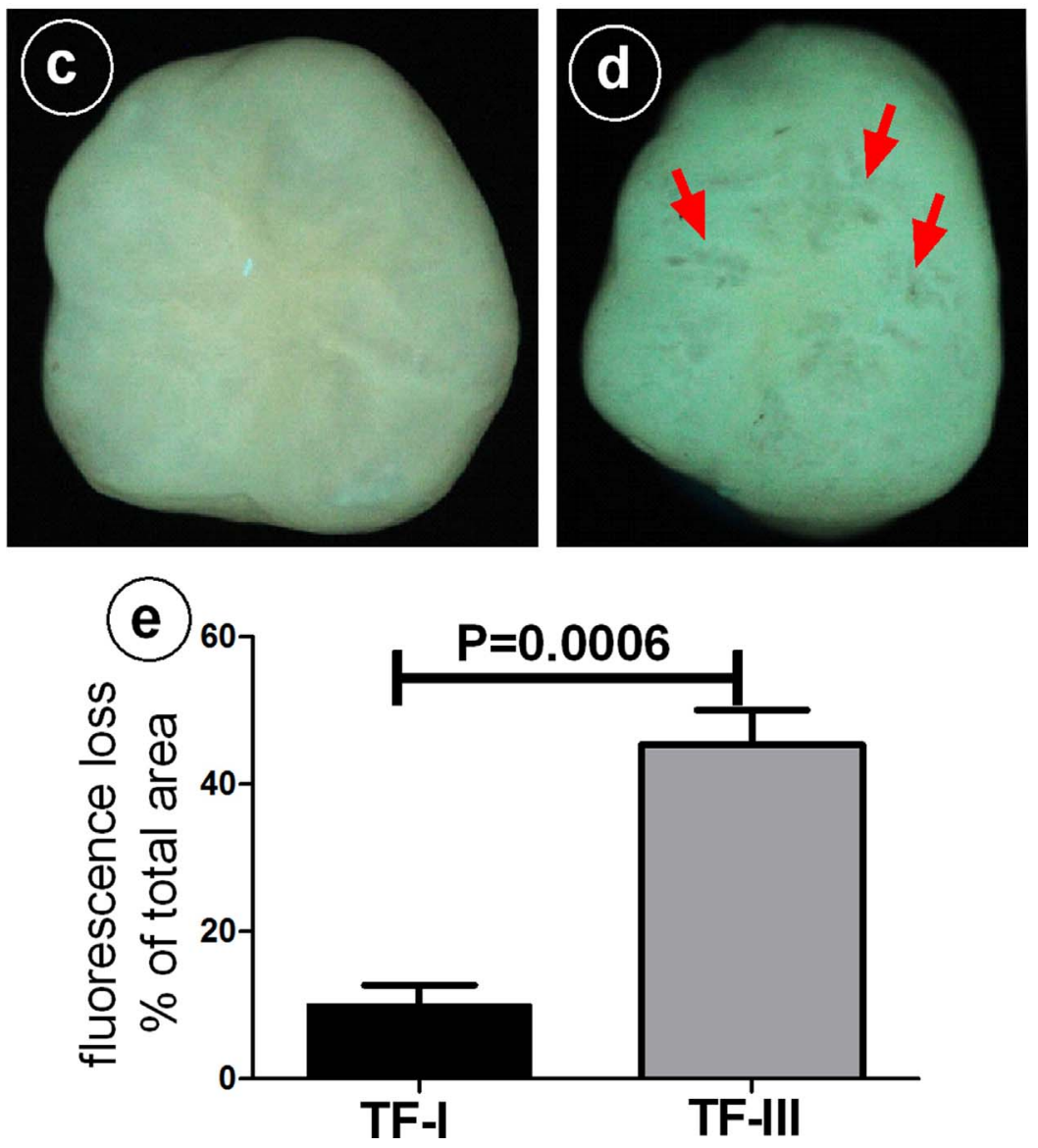

to mineralize till completion (Smith, 1998). Enamel hypomineralization, seen after exposure of mice or rats to drinking water containing $25 \mathrm{ppm}$ fluoride or more suggests that fluoride impairs calcium phosphate crystal growth preeruptively (Angmar-Månsson \& Whitford, 1984). Isolated and confluent pits seen in severely affected human fluorotic teeth may be post-eruptively by mechanical trauma of hypomineralized surface enamel (Thylstrup, 1983). Several mechanisms have been proposed responsible for formation of fluorotic enamel, e.g. impaired transport of mineral ions, reduced expression of mineral ion transporters (Bronckers, Jalali, \& Lytton, 2017) or reduced secretion of proteases but not their direct inhibition by fluoride (Tye, Antone, \& Bartlett, 2011). Recently, it was proposed that enamel fluorosis may develop due to generation of extra protons by fluoride-induced acceleration of crystal formation (Lyaruu et al., 2014) seen as hypermineralized lines in rodent enamel after a high dose of fluoride or in tooth organ cultures exposed to fluoride in vitro (Bronckers \& Wöltgens, 1985).

Ameloblasts appear to have the machinery to produce and secrete bicarbonates (Bori et al., 2016; Bronckers et al., 2011; Lacruz, Nanci, Kurtz, Wright, \& Paine, 2010; Smith, 1998). In mice fluorosis is far more pronounced when $\mathrm{pH}$ buffering by ameloblasts is disrupted by null mutation of $\mathrm{pH}$ regulators, supporting the relevance of buffering protons during mineralization in forming enamel (Lyaruu et al., 2014).

Here we examined whether hypermineralization could also be assessed by MicroCT in developing molar enamel of humans exposed to fluoride. To avoid post-eruptive changes in enamel, we used in this study impacted teeth. We also examined the enamel of impacted human 
teeth for the presence of surface irregularities to see if pits and grooves could develop pre-eruptively. Based on reports that long-term exposure of rats to $100 \mathrm{ppm}$ fluoride in drinking water reduced the thickness of enamel (Smith et al., 1993), we furthermore measured the thickness of the enamel layer and the crown dimensions in these human and fluorotic mouse teeth.

\section{Methods and materials}

\subsection{Human material}

Unerupted upper third molars $(\mathrm{n}=12)$ were collected from donors 16-30 years-old attending the Oral Surgery clinics at the Dental Faculty, Universidad El Bosque in Bogotá, Colombia (an area with high prevalence of fluorosis and 180-220 mg F/ kg added to salt since 1989) (Franco et al., 2005). All subjects used twice/day fluoridated toothpaste (1000-1500 ppm F). Daily average fluoride intake by subjects from Bogotá has been reported as $0.11 \pm 0.10 \mathrm{mg} \mathrm{F} / \mathrm{kg}$ body weight $(1.43 \pm 1.14 \mathrm{mg} \mathrm{F} /$ day) based on an assessment by questionnaire, filled in by subjects with permission of their parents if the subjects were younger than 18 year. It included questions on social-demographical data, oral hygiene habits, fluoride-use habits and the instructions they received for the oral care. Two trained and experienced examiners (SM, GC) visually assessed the teeth with signs of fluorosis using the TF index (Thylstrup \& Fejerskov, 1978), and agreed in the severity score. From the pool of teeth, 12 were selected from Bogota: TF-I/II $(n=6)$, TF-III/ IV $(n=6)$. Since it was not possible to obtain control teeth completely free from any sign of fluorosis in Bogota age-matched-non-fluorotic human third molar control teeth (donors $16-30$ years-old) $(n=3)$ were collected at the VU Medical Centre, Amsterdam, The Netherlands, used as non-fluorotic negative controls. Donors signed a tooth-donation term and the study was approved by the Ethical Board of Universidad El Bosque (UB.267.2010) and VU-Medical Centre, Amsterdam. Teeth were extracted for orthodontic or prophylactic reasons. Immediately after extraction, a pool of molars undamaged by the surgical procedure were rinsed with tap water and put in phosphate-buffered saline with $0.02 \%$ thymol (PBS-T). At the lab, soft tissue and blood residues were removed with scalpel and prophylactic brush and stored at $4{ }^{\circ} \mathrm{C}$ in PBS-T.

\subsection{Animals}

Three-week old mice (C57Bl) were divided into 2 groups and given drinking water containing either 0 or $100 \mathrm{mg}$ of $\mathrm{F} / \mathrm{L}(221 \mathrm{mg} / \mathrm{L} \mathrm{NaCl})$ for 6 weeks. After euthanasia of the mice hemimandibles were excised, snap-frozen in liquid nitrogen, freeze-dried, and mounted in a holder for Micro-CT scanning. All experiments were approved by the Committee for Animal Care (Vrije Universiteit Amsterdam; ACTA-1201). The methods were carried out in accordance with the approved guidelines. Plasma levels of the mice at time of sacrifice were $10 \mu \mathrm{mol} /$ $\mathrm{L}$ in fluorotic mice and $2 \mu \mathrm{mol} / \mathrm{L}$ in controls.

\subsection{Quantitative light-induced fluorescence (QLF) analysis}

In areas of the enamel where hypomineralization was present, a decrease of fluorescence intensity could be seen (Fig. 1d). Photographs of these fluorescent areas were taken from all surfaces of the crowns of the extracted molars using a QLF-D camera (Inspector Research Systems BV, Amsterdam, The Netherlands). It consists of a Canon 450-D SLR camera equipped with an illumination tube and uses an excitation wavelength of $405 \pm 20 \mathrm{~nm}$ and filtering optics in front of the camera lens. The photographs were taken using dedicated software (C3 v 1.25; Inspektor Research Systems) in a dark room with fixed camera settings (shutter speed 1/160e; aperture value 5.6; ISO1600). The tooth surfaces were washed in deionized water and dried before the photographs were taken. The roots of the molars were placed in a clay block to fix the molars and to standardize the distance between the teeth and the lens of the camera. The photographs were analyzed by a single examiner using Image-J software (Image-J 1.33u software; http://rsb.info.nih.gov/ij/ index.html). The fluorotic surface (white spot size) of a tooth was calculated as the affected enamel (dark non-fluorescent area of the crown area in $\mathrm{mm}^{2}$ ) divided by the total area of the crown surface (in $\mathrm{mm}^{2}$ ) times 100 .

\subsection{Micro-CT}

The teeth (human and mice) were scanned with $\mu$ CT 40 (Scanco Medical AG, Bruttisellen, Switzerland). This scanner is calibrated weekly using a phantom with densities from 0 to $3000 \mathrm{mg} \mathrm{HA} / \mathrm{cm}^{3}$. Teeth were mounted in a holder and placed in the scanner in such a manner to minimize the FOV (field of view). Voxels near the enamel surface were excluded to preclude Micro-CT partial volume effect. The integration time was set at $300 \mathrm{~ms}$, the beam intensity at $55 \mathrm{kV}$, the current at $145 \mu \mathrm{A}$ and the resolution set at $18 \mu$ for both mice and human teeth. An internal standard made of solid-sintered apatite (5-mm diameter, $1.5-2.0 \mathrm{~mm}$ thick) with density of $2.9 \pm 0.2 \mathrm{~g} / \mathrm{mL}$ (a gift from Himed; http://www.himed.com) was used as high-density standard. Three-dimensional (3D) reconstructions were made using the cone beam reconstruction algorithm. Using two-dimensional-horizontal cross-sections, mean mineral density was measured at nine circular regions of interest (Fig. 3i, insert). The shape of the surrounding bone and the position of the molar roots were used as landmarks to obtain the same stages of development for different animals. The mineral density was quantified at two locations throughout the enamel thickness: at the central and mesial/lateral side of the enamel. At each region three locations were selected: outer enamel (OE), mid-enamel (ME, half way between enamel surface and dentin-enamel junction DEJ), and inner enamel (IE, near DEJ) (Clementino-Luedemann \& Kunelmann, 2006) (Fig. 3i). For human teeth density measurements (expressed as $\mathrm{mg}$ hydroxyapatite $/ \mathrm{cm}^{3}$ ) were made at $540 \mu \mathrm{m}$ intervals and plotted for each tooth individually (slice number). For mouse incisors beginning at the apical part and moving toward the tip, cross-sectioned images were collected at sequential intervals of $300 \mu \mathrm{m}$ in maturation-stage and $60 \mu \mathrm{m}$ in secretory-stage enamel. In wild-type mouse mandibular incisors, enamel maturation begins approximately at the level where an imaginary line drawn between first and second molars intersects the incisor; in that area, the mineral density of secretory-stage enamel equals that of dentin (approximately $1300 \mathrm{mg} \mathrm{HA} / \mathrm{cm}^{3}$ ), and the dentin layer is around $100 \mu \mathrm{m}$ wide. All the teeth (mouse and human) were run by the same Micro-CT and operated and calculated by the same individuals.

\subsection{Measurement of enamel thickness}

The teeth were scanned with an EasyTom Micro-CT (RX Solutions, France) at the Centre de Microtomographie (IC2MP, iPHEP, University of Poitiers). During the scanning procedure beam intensity was set at $70 \mathrm{kV}$ and tube current at $230 \mu \mathrm{A}$. Each molar was acquired with 992 projections resulting in 1299 slices using cone-beam reconstruction algorithm. The isovoxel size was set to $0.015 \mathrm{~mm}$. High-resolution micro-computed tomography (HR- $\mu \mathrm{CT}$ ) images taken of the original molars were used to compute virtual 3D models of the enamel cap. The crown enamel volume data was converted into a polygonal surface, a 3D irregular array of contiguous triangles corresponding to a set of tridimensional points or nodes connected by edges (Guy, Gouvard, Boistel, Euriat, \& Lazzari, 2013). This operation allowed the partition of the crown enamel into its inner (enamel-dentin-junction; EDJ) and outer (outer enamel surface; OES) components. For each molar, linear mesial, occlusal and lateral enamel thickness was measured following procedures developed by (Guy et al., 2013). Mesio-distal and buccolingual dimensions of the teeth were measured according to the method described before (Moorrees, Thomsen, Jensen, \& Yen, 1957). The thickness of the incisor enamel layer was measured as the shortest 
distance from the line perpendicular from dentin-enamel junction (DEJ) to the enamel surface.

\subsection{Statistical analysis}

All values are presented as means \pm standard error of mean (SEM). Data were analyzed using an unpaired Student $t$-test with $\mathrm{p}<0.05$ considered statistically significant.

\section{Results}

\subsection{Quantification of white spots on occlusal surface of human fluorotic molars by $Q L F$}

First, the enamel was examined for defects visually under white light using a stereo microscope $(4-10 \times)$. In TF-I/II and control group no white spots were apparent when enamel was examined wet. After drying, chalky-white spots became visible on the teeth of the TF-I/II group but not in the Amsterdam non-fluorotic control group. In the TFIII/IV group the chalky-white areas were visible both wet and after drying (Fig. 1a, b). Also with 4-10 $\times$ magnification we did not find any pits or irregularities in the enamel surface of either TF-I/II or TF-III/IV groups.

Subsequently, the occlusal surfaces of the molars were examined by QLF, a technique with which defects are seen as non-fluorescent (dark) areas (Fig. 1d). Using QLF, the TF-III/IV group contained a 4.5 fold higher score $(45 \% \pm 5 \%$ of the occlusal surface, $n=4)$ as the TF-I/II group $(10 \% \pm 3 \%, \mathrm{n}=4)$ (Fig. 1c-e). No non-fluorescent areas could be seen with QLF in the Amsterdam non-fluorotic control group (data not shown).

\subsection{Hypomineralization in human fluorotic enamel measured by Micro-CT}

Micro-CT was used to determine the effect of fluoride on enamel mineral content. It is a noninvasive method which allows virtual sectioning of the teeth. The 3D image analytical tools offer the opportunity to characterize the morphology and properties of dental tissue in a quantitative way.

Mineral density measurements in 3D-reconstructed molar models showed the highest density in the tip of the cusps of the control teeth (most calcified) and a decrease in cervical direction and toward fissure base. Although the fluorotic teeth followed the same pattern, the cusp tips were less mineralized. Moreover, the higher the TF index grade the more areas were found that halfway the cusp height were less mineral dense (both lingually and buccally; Fig. 2b-d respectively). Weak hypermineralized lines were noticed in fluorotic teeth (black arrows in Fig. 2f-h)

In human TF-III/IV molars the enamel of the cervical region near Cement-Enamel Junction (CEJ) appeared to be the least mineralized (red arrows in Fig. 2h). Hypomineralized subsurface layers were detected in fluorotic enamel of TF-III/IV upper molars (Fig. 2d). In cross-sections through these areas, the subsurface defects seemed to be relatively superficial without extending deeper (Fig. 2h). In deeper layers multiple weak hypermineralized lines separated by hypomineralized areas ran parallel to the hypomineralized surface (Fig. 2h).

Fig. $2 \mathrm{k}$ shows the distribution of mineral density in human fluorotic enamel from the outer to the inner enamel layer in the control group $(\mathrm{n}=3)$, and the TF-I/II $(\mathrm{n}=6)$ and TF-III/IV $(\mathrm{n}=6)$ groups represented as 3D line plots. In both fluorotic and control groups, the lowest density was near DEJ (Dentin-Enamel-junction) but density increased from DEJ towards the outer enamel surface (Fig. 2j). However, in human fluorotic enamel at different depths the mineral densities between the three groups (control and the two fluorotic groups) did not show statistical differences (Fig. 2j).

\subsection{Hypomineralization in mouse fluorotic enamel measured by Micro-CT}

Virtual reconstruction of fluorotic enamel in the developing mouse incisor showed that the changes seen at the enamel surface were developmental-stage dependent; at late maturation fluorotic mouse enamel exhibited basically the same enamel defects as human TF-III enamel (a patchy distribution of hypomineralized subsurface; hypermineralized areas at various depths of the enamel layer and the enamel near the CEJ markedly less mineralized Fig. 3e-h; Fig. 2f). At early maturation mouse fluorotic enamel showed a surface that was hypermineralized with a hypomineralized subsurface and weakly hypermineralized patchy areas (Fig. 3f).

In developing mouse incisors mineral density in control and fluorotic enamel increased in sigmoidal pattern from secretory to the late maturation (Fig. 3k). In fluorotic mice enamel the slope of the mineral increase became steeper at the onset of early maturation (Fig. 3k).

Quantification of the mineral density in mouse enamel showed that the distribution patterns of density differed between fluorotic and control groups including (Fig. 3 j): (1) a $31 \%$ reduction ( $<<0.0001$ ) in the total mineral density at the maturation stage in fluorotic mice. (2) A $9 \%(p=0.004)$ lower mineral density of maturation enamel mesially and laterally than centrally in fluorotic enamel but not in wild-type enamel. (3) Unlike to human, in mouse fluorotic enamel the proportion of changes in mineral density was the same in outer (OE), mid (ME) and inner (IE) enamel, all reduced by $\sim 30 \%$ ( $<<0.0001$ ).

\subsection{Enamel thickness and crown size in human fluorotic enamel measured by Micro-CT}

To investigate the effect of fluoride on enamel thickness in fluorotic human teeth, we made virtual slices through the mesial cusps and measured linear thickness in three regions (cusp tip, maximum occlusal and maximum lateral thickness) (Fig. 4a-i). The differences in enamel layer thickness between TF-I/II and TF-III/IV are summarized in box plots (Fig. 4e, f). In TF-III/IV teeth, the average occlusal enamel layer was approximately $10 \%$ thinner at the buccal side (Fig. $4 \mathrm{i}$ ) and $14 \%$ thinner at the lingual side (Fig. 4h) in comparison to TF-I teeth but values were not statistically significant.

The crown size of the most fluorotic human molars differed from that of the least fluorotic molars measured occlusally as the mesio-distal (double-pointed black arrow in Fig. 4g) and bucco-lingual length (red double-pointed arrow in Fig. 4g). The mesio-distal length of the TF-III/ IV group was significantly smaller than those of TF-I/II group (18\%; $\mathrm{P}=0.02$; Fig. $4 \mathrm{i}$ ); no differences were detected in the bucco-lingual size between the two groups (Fig. 4h). In fluorotic mice the enamel layer of the incisor was $7 \%$ thinner than in control mice but was not statically significant $(\mathrm{p}=0.5)$ (Fig. $4 \mathrm{k}, 1)$.

\section{Discussion}

Currently, in 40 countries fluoride is added to the drinking water as cariostatic agent. Where water fluoridation is not possible, salt fluoridation is used as a next-best option. Based on the study in major Colombian cities, the mean total daily fluoride intake ( $\mathrm{mg} \mathrm{F} /$ day), from salt (180-220 mg F/ $\mathrm{kg}$ ), water $(0.08 \mathrm{ppm})$ and toothpaste, was the highest in children in Medellina and Bogota ( $1.73 \mathrm{mg} \mathrm{F} /$ day and $1.43 \mathrm{mg} \mathrm{F} /$ day respectively) (Franco et al., 2005). In the Netherlands since 1976 no fluoride is added to the drinking water. Therefore teeth from Amsterdam subjects were used as non-fluorotic controls group to compare the mineral distribution with that in the fluorotic group from Bogota.

To the best of our knowledge no quantified Micro-CT data have been published to examine mineralization defects in human fluorotic enamel. Micro-CT analysis of non-fluorotic human molars showed that mineral-density in the cusp tips was higher than enamel in the other 

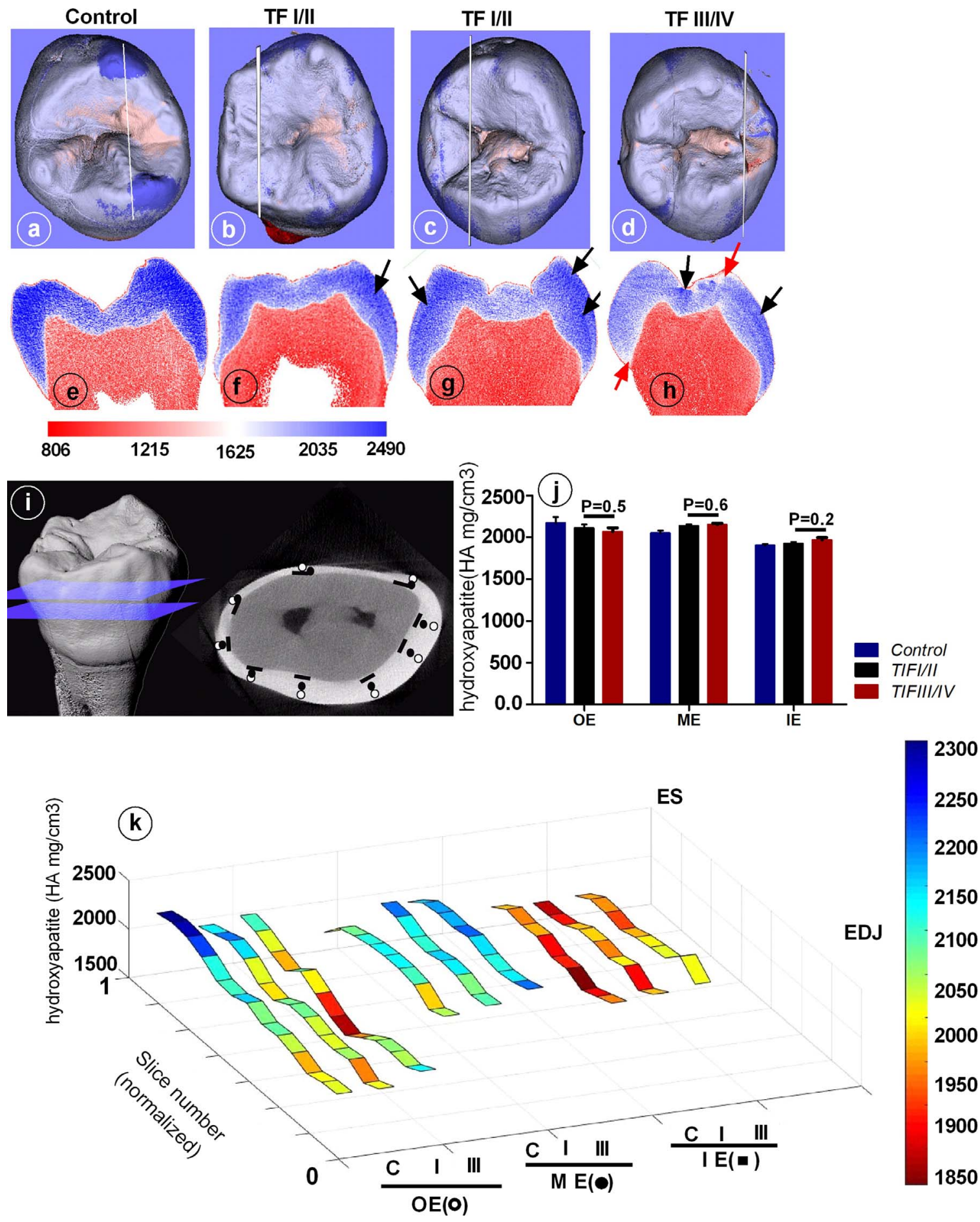

Fig. 2. Enamel mineral density in human fluorotic enamel determined by Micro-CT.

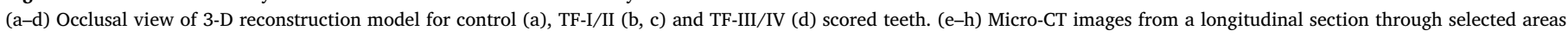

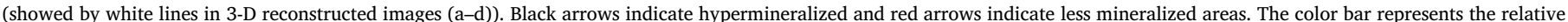

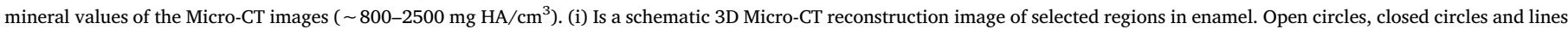

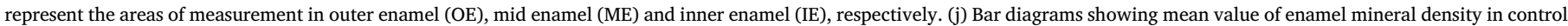

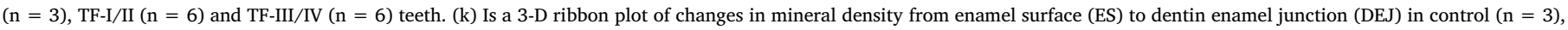

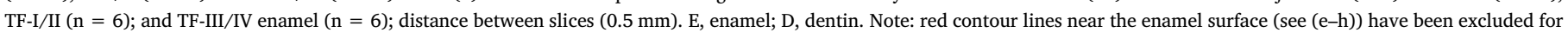
all the measurements. (For interpretation of the references to color in this figure legend, the reader is referred to the web version of this article.)

parts. In human fluorotic enamel we found hypermineralized patches and weak lines. We cannot exclude the possibility that some lines (e.g. with orientation different from the usual growth lines) are artefacts. Many lines in human fluorotic enamel resembled the lines seen in fluorotic enamel of rodents chronically exposed to low doses of fluoride or injected with a high dose of fluoride and examined by different techniques (Transmission Electron Microscopy, microradiography and backscatter scanning electromicroscopy; Angmar-Månsson et al., 1977; Fejerskov et al., 1994; Kierdorf \& Kierdorf, 1997; Lyaruu et al., 2014; Yaeger, 1966). The data suggest that enamel mineral defects in human 

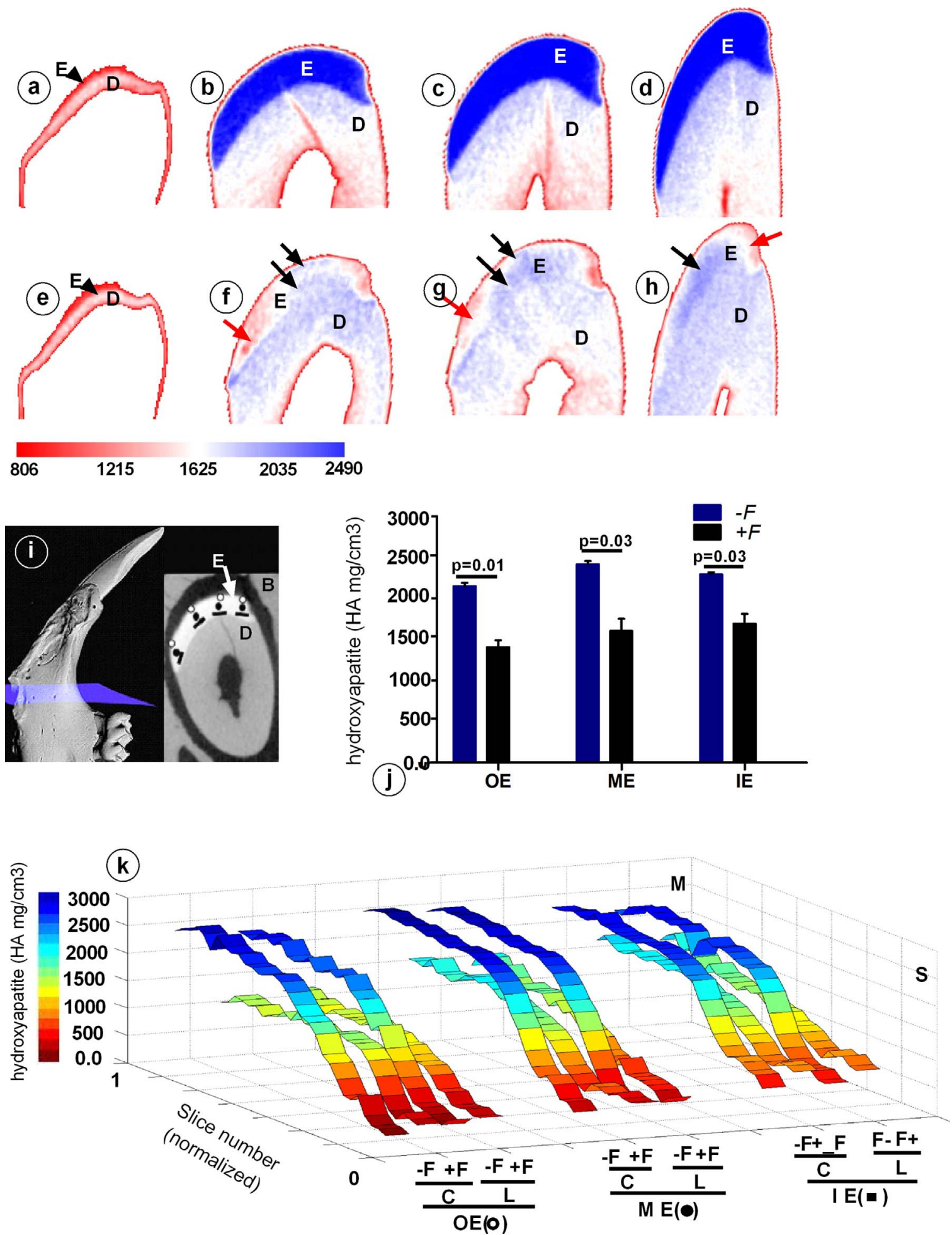

Fig. 3. Mineral density in fluorotic mouse enamel from secretory stage (S, right, red) to fully mature (M) enamel (blue).

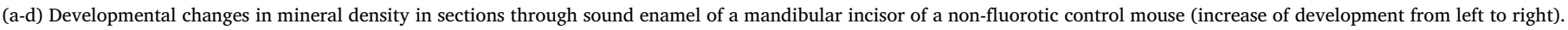

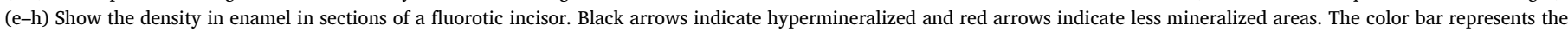

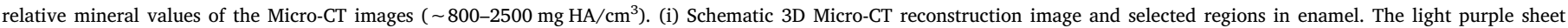

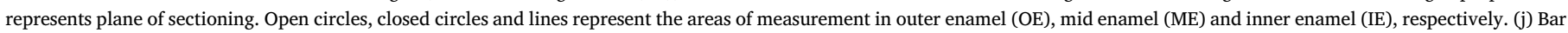

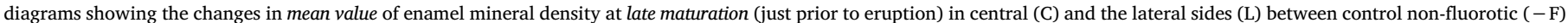

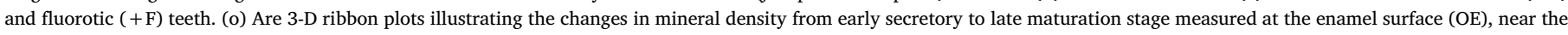

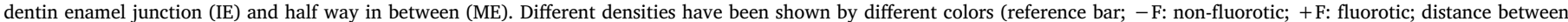

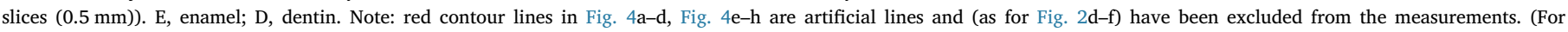
interpretation of the references to color in this figure legend, the reader is referred to the web version of this article.) 
TFI
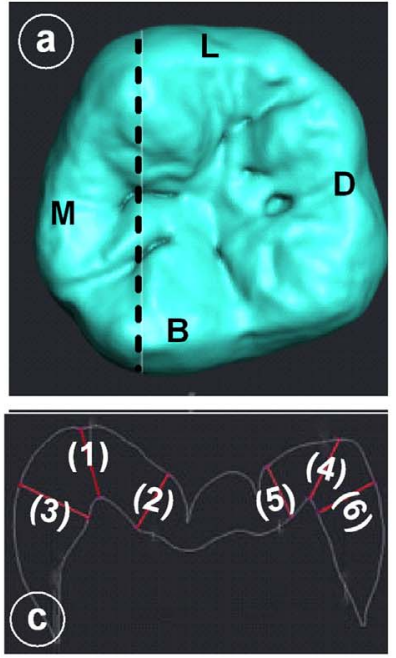

TFIII
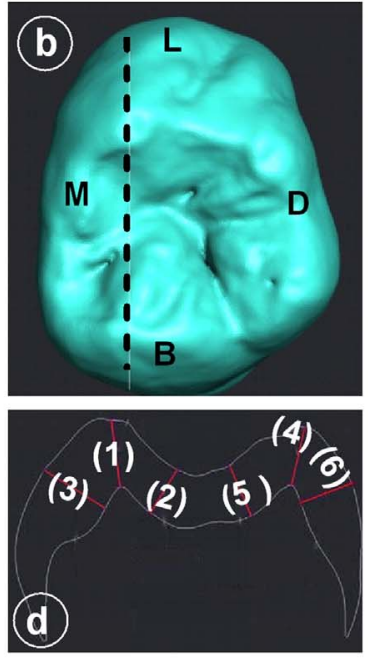
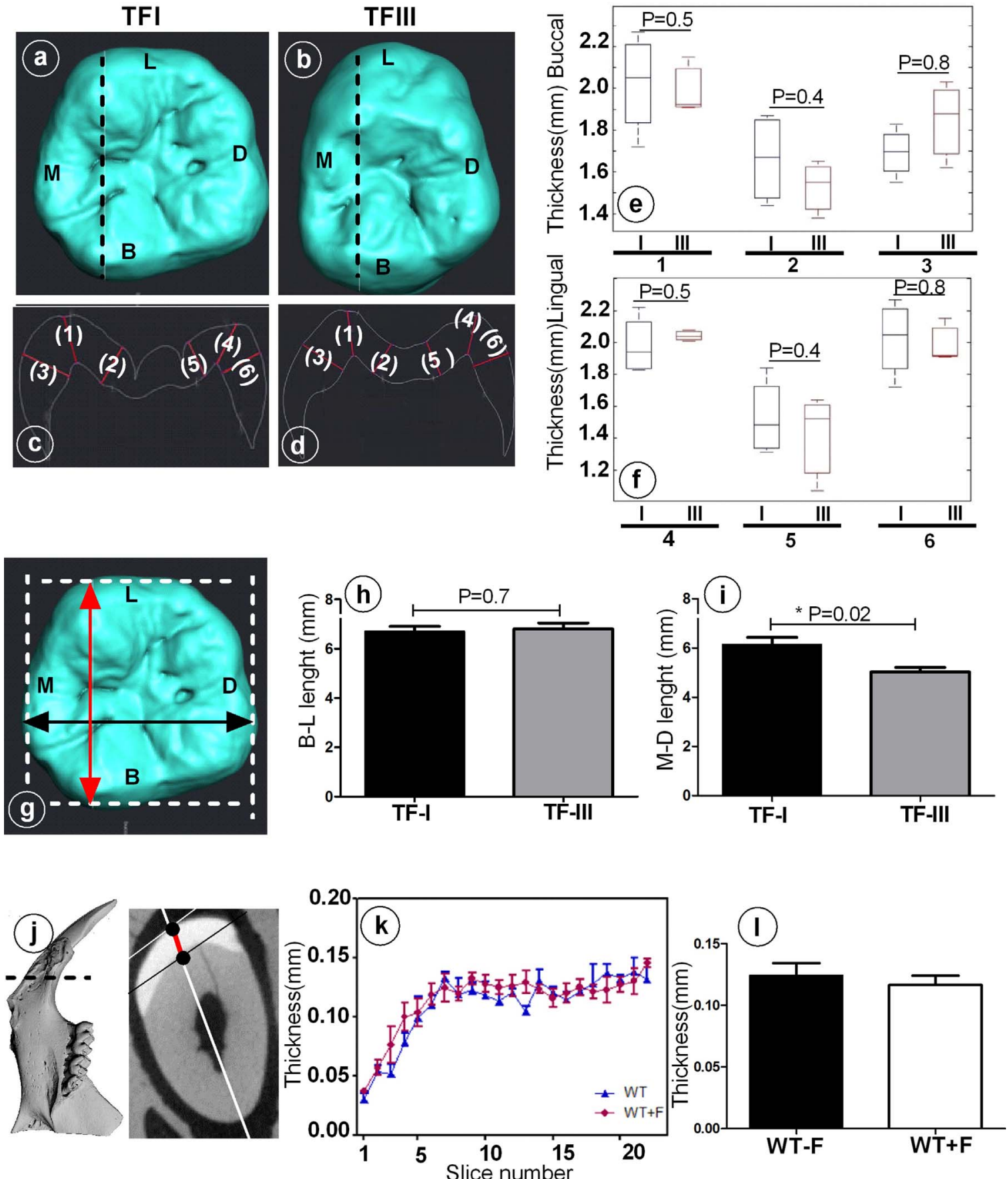

Fig. 4. Enamel thickness (a-f) and crown size (g-i) of fluorotic human molars (TF-I and TF-III) and enamel thickness in fluorotic and nonfluorotic control mouse incisors (j-l).

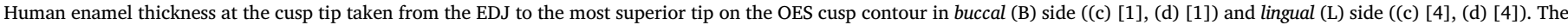

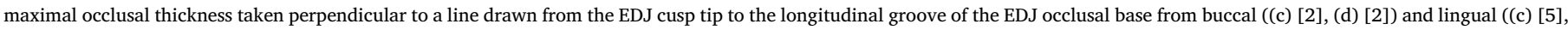

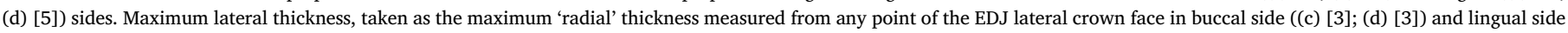

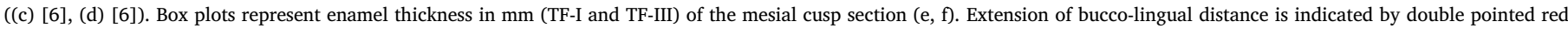

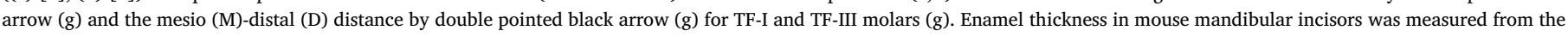

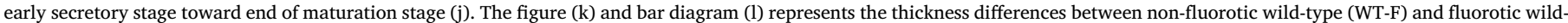

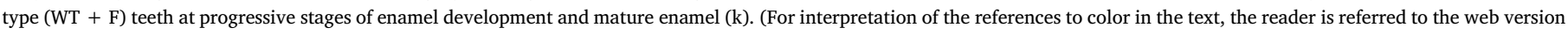
of this article.)

fluorotic enamel are similar to those in fluorotic mouse enamel.

In mature (impacted) human fluorotic enamel we found that the surface enamel was not hypermineralized. In fluorotic mouse enamel using backscatter scanning electron microscopy the enamel surface appeared hypermineralized only at early maturation after which these lines became obscured by ongoing mineral deposition (Lyaruu et al., 2014). The difference in surface hypermineralization between human and mouse fluorotic enamel could be due to (1) differences in resolution of the technique used (SEM, Micro-CT); (2) changes in the rate of enamel development that is higher in rodent incisors than in human teeth; (3) differences in developmental stages, exposure time and in F dose.

Enhanced hypermineralization of surface enamel and more pronounced hypermineralization lines in mouse incisors were found when secretion of bicarbonates by ameloblasts was disrupted (i.e. in Ae2 null 
mice) suggesting that effective buffering reduces fluorotic changes (Lyaruu et al., 2014). The present observation that also human fluorotic TF-IV enamel was diffusely hypomineralized but contained weak hypermineralized lines or small areas that were hypermineralized suggests that - similar to rodents - also in developing human fluorotic enamel fluoride transiently accelerates mineral formation, causing a local acidification of enamel. Further evidence that hypermineralization could take place in developing fluorotic human enamel is suggested by slightly elevated (not statistically significant) levels of phosphorus detected by micro-Raman spectrophotometry (Zavala-Alonso et al., 2012).

We did not measure in human fluorotic teeth the occurrence of more acidic enamel in maturation stage than in non-fluorotic teeth. That would require a different type of study. In fluorotic rats and mice modulation bands are wider after staining with $\mathrm{pH}$ dye solutions suggesting fluorotic enamel is more acidic (Bronckers, Lyaruu, \& DenBesten, 2009) possibly due to stimulation of mineralization by fluoride (Brown, Eidelman, \& Tomazic, 1987). This acidification presumably is neutralized by binding of protons to amelogenins and in maturation stage by enhanced secretion of bicarbonates in exchange for $\mathrm{Cl}^{-}$in enamel fluid (Bori et al., 2016; Guo et al., 2015). During long term exposure to fluoride the ongoing demand to secrete more buffer likely depletes $\mathrm{Cl}^{-}$levels in enamel, reduces the capacity of ameloblasts to secrete bicarbonates, delays ameloblast modulation and eventually results in an overall hypomineralization (Bronckers et al., 2017; Bronckers \& Lyaruu, 2017). Interestingly analysis of human fluorotic teeth by secondary ion mass spectrometry and X-ray microanalysis showed the same compositional changes in the superficial layers as reported in fluorotic mouse enamel: reduction in $\mathrm{Cl}^{-}$level, along with a slight increase in $\mathrm{K}^{+}$and $\mathrm{F}^{-}$(Jälevik, Odelius, Dietz, \& Norén, 2001). These similarities suggest the same mechanisms leading to fluorotic enamel are operating in humans and in rodents.

Our results furthermore showed that a moderate daily dose of fluoride to children with developing enamel slightly (but not significantly) reduced the thickness of enamel in mesial cusps along with a (statistically significant) decrease of mesio-distal length of the tooth also reported in rodents (Smith et al., 1993; Zhou, Zaki, \& Eisenmann, 1996). Reduction of the thickness of enamel in rodents was correlated by F-induced accumulation of matrix and its intracellular degradation (Bronckers, Lyaruu, Bervoets, \& Woltgens, 2002; Monsour et al., 1989).

The results of the current study can be interpreted as indirect evidence that the primary effect of fluoride on enamel formation is stimulation of mineral formation which releases excess of protons to which ameloblasts immediately respond.

\section{Conflict of interest}

The authors declare no potential conflicts of interest with respect to the authorship and/or publication of this article.

\section{References}

Angmar-Månsson, B., \& Whitford, G. M. (1984). Enamel fluorosis related to plasma F levels in the rat. Caries Research, 18(1), 25-32.

Angmar-Månsson, B., Ericsson, Y., \& Ekberg, O. (1977). Plasma fluoride and enamel fluorosis. Calcified Tissue Research, 22(1), 77-84.

Bori, E., Guo, J., Rácz, R., Burghardt, B., Földes, A., Kerémi, B., et al. (2016). Evidence for bicarbonate secretion by ameloblasts in a novel cellular model. Journal of Dental Research, 95(5), 588-596.

Bronckers, A., \& Lyaruu, D. (2017). Magnesium, pH regulation and modulation by mouse ameloblasts exposed to fluoride. Bone, 94, 56-64.

Bronckers, A., \& Wöltgens, J. (1985). Short-term effects of fluoride on biosynthesis of enamel-matrix proteins and dentine collagens and on mineralization during hamster tooth-germ development in organ culture. Archives of Oral Biology, 30(2), 181-191.

Bronckers, A., Lyaruu, D., Bervoets, T., \& Wöltgen, J. (2002). Fluoride enhances in tracellular degradation of amelogenins during secretory phase of amelogenesis of hamster teeth in organ culture. Connective Tissue Research, 43(2-3), 456-465.

Bronckers, A., Lyaruu, D., \& DenBesten, P. (2009). The impact of fluoride on ameloblasts and the mechanisms of enamel fluorosis. Journal of Dental Research, 88(10), 877-893.

Bronckers, A., Guo, J., Zandieh Doulabi, B., Bervoets, T., Lyaruu, D., Li, X., et al. (2011). Developmental expression of solute carrier family 26A member 4 (SLC26A4/pendrin) during amelogenesis in developing rodent teeth. European Journal of Oral Sciences, 119(s1), 185-192.

Bronckers, A., Jalali, R., \& Lytton, J. (2017). Reduced protein expression of the $\mathrm{Na}^{+}$ $\mathrm{Ca}^{2+} / \mathrm{K}^{+}$exchanger (Slc24a4) in apical plasma membranes of maturation ameloblasts of fluorotic mice. Calcified Tissue International, 100(1), 80-86.

Brown, W., Eidelman, N., \& Tomazic, B. (1987). Octacalcium phosphate as a precursor in biomineral formation. Advances in Dental Research, 1(2), 306-313.

Clementino-Luedemann, T. N., \& Kunelmann, K. H. (2006). Mineral concentration of natural human teeth by a commercial Micro-CT. Dental Materials Journal, 25(1), $113-119$.

DenBesten, P., Yan, Y., Featherstone, J., Hilton, J., Smith, C., \& Li, W. (2002). Effects of fluoride on rat dental enamel matrix proteinases. Archives of Oral Biology, 47(11), 763-770.

DenBesten, P. (1986). Effects of fluoride on protein secretion and removal during enamel development in the rat. Journal of Dental Research, 65(10), 1272-1277.

Everett, E., McHenry, M., Reynolds, N., Eggertsson, H., Sullivan, J., Kantmann, C., et al. (2002). Dental fluorosis: Variability among different inbred mouse strains. Journal of Dental Research, 81(11), 794-798.

Fejerskov, O., Larsen, M. J., Richards, A., \& Baelum, V. (1994). Dental tissue effects of fluoride. Advances in Dental Research, 8(1), 15-31.

Franco, Á. M., Martignon, S., Saldarriaga, A., González, M. C., Arbeláez, M. I., Ocampo, A., et al. (2005). Total fluoride intake in children aged 22-35 months in four Colombian cities. Community Dentistry and Oral Epidemiology, 33(1), 1-8.

Guo, J., Lyaruu, D., Takano, Y., Gibson, C., DenBesten, P., \& Bronckers, A. (2015). Amelogenins as potential buffers during secretory-stage amelogenesis. Journal of Dental Research, 94(3), 412-420.

Guy, F., Gouvard, F., Boistel, R., Euriat, A., \& Lazzari, V. (2013). Prospective in (Primate) dental analysis through tooth 3D topographical quantification. PLoS One, 8(6), e66142.

Jälevik, B., Odelius, H., Dietz, W., \& Norén, J. (2001). Secondary ion mass spectrometry and X-ray microanalysis of hypomineralized enamel in human permanent first molars. Archives of Oral Biology, 46(3), 239-247.

Kierdorf, H., \& Kierdorf, U. (1997). Disturbances of the secretory stage of amelogenesis in fluorosed deer teeth: A scanning electron-microscopic study. Cell and Tissue Research, 289(1), 125-135.

Lacruz, R. S., Nanci, A., Kurtz, I., Wright, J. T., \& Paine, M. L. (2010). Regulation of pH during amelogenesis. Calcified Tissue International, 86(2), 91-103.

Lyaruu, D., Medina, J., Sarvide, S., Bervoets, T., Everts, V., DenBesten, P., et al. (2014) Barrier formation potential molecular mechanism of enamel fluorosis. Journal of Dental Research, 93(1), 96-102.

Monsour, P. A., Harbrow, D. J., \& Warshawsky, H. (1989). Effects of acute doses of sodium fluoride on the morphology and the detectable calcium associated with secretory ameloblasts in rat incisors. Journal of Histochemistry \& Cytochemistry, 37(4), 463-471.

Moorrees, C. F., Thomsen, S.Ø., Jensen, E., \& Yen, P. K. J. (1957). Mesiodistal crown diameters of the deciduous and permanent teeth in individuals. Journal of Dental Research, 36(1), 39-47.

Smith, C., Nanci, A., \& Denbesten, P. (1993). Effects of chronic fluoride exposure on morphometric parameters defining the stages of amelogenesis and ameloblast modulation in rat incisors. The Anatomical Record, 237(2), 243-258.

Smith, C. (1998). Cellular and chemical events during enamel maturation. Critical Reviews in Oral Biology \& Medicine, 9(2), 128-161.

Thylstrup, A., \& Fejerskov, O. (1978). Clinical appearance of dental fluorosis in permanent teeth in relation to histologic changes. Community Dentistry and Oral Epidemiology, 6(6), 315-328.

Thylstrup, A. (1983). Posteruptive development of isolated and confluent pits in fluorosed enamel in a 6-year-old girl. European Journal of Oral Sciences, 91(4), 243-246.

Tye, C. E., Antone, J. V., \& Bartlett, J. D. (2011). Fluoride does not inhibit enamel protease activity. Journal of Dental Research, 90(4), 489-494.

Walton, R., \& Eisenmann, D. (1974). Ultrastructural examination of various stages of amelogenesis in the rat following parenteral fluoride administration. Archives of Oral Biology, 19(2).

Yaeger, J. A. (1966). The effects of high fluoride diets on developing enamel and dentin in the incisors of rats. Developmental Dynamics, 118(2), 665-683.

Zavala-Alonso, V., Loyola-Rodríguez, J. P., Terrones, H., Patiño-Marín, N., MartínezCastañón, G. A., \& Anusavice, K. (2012). Analysis of the molecular structure of human enamel with fluorosis using micro-Raman spectroscopy. Journal of Oral Science, 54(1), 93-98.

Zhou, R., Zaki, A., \& Eisenmann, D. (1996). Morphometry and autoradiography of altered rat enamel protein processing due to chronic exposure to fluoride. Archives of Oral Biology, 41(8-9), 739-747. 


\section{Update}

\section{Archives of Oral Biology}

Volume 84, Issue, December 2017, Page 177

DOI: https://doi.org/10.1016/j.archoralbio.2017.09.003 
Corrigendum

\title{
Corrigendum to "Mineralization-defects are comparable in fluorotic
} impacted human teeth and fluorotic mouse incisors" [Archives of Oral Biology 29 (July (83)) (2017) 214-221]

\author{
Rosita Jalali ${ }^{\mathrm{a}, *}$, Franck Guy ${ }^{\mathrm{b}}$, Samaneh Ghazanfari ${ }^{\mathrm{c}}$, Don Lyaruu ${ }^{\mathrm{a}}$, Leo van Ruijven ${ }^{\mathrm{a}}$, \\ Pamela DenBesten $^{\mathrm{d}}$, Stefania Martignon ${ }^{\mathrm{e}}$, Gina Castiblanco ${ }^{\mathrm{e}}$, Antonius Bronckers ${ }^{\mathrm{a}}$

\footnotetext{
a Department of Oral Cell Biology, Academic Centre for Dentistry Amsterdam, University of Amsterdam, and MOVE Research Institute, VU University Amsterdam, Amsterdam, Netherlands

b CNRS INEE UMR 7262 - IPHEP, Institut de Paléoprimatologie et Paléontologie Humaine, Evolution et Paléoenvironnements, Université de Poitiers - Faculté des Sciences, Bât. B35 -TSA 51106, 6 rue Michel Brunet, 86073, Poitiers, Cedex 9, France

${ }^{c}$ Department of Orthopaedic Surgery - VU Medical Centre, Amsterdam the Netherlands; MOVE Research Institute Amsterdam, Amsterdam, Netherlands and the AachenMaastricht Institute for Biobased Materials, Faculty of Humanities and Sciences, Maastricht University, Maastricht, Netherlands

d Department of Orofacial Sciences, School of Dentistry, University of California, San Francisco, CA 94143-0422, USA

${ }^{\text {e } U N I C A ~-~ C a r i e s ~ R e s e a r c h ~ U n i t, ~ R e s e a r c h ~ V i c e-r e c t o r y, ~ U n i v e r s i d a d ~ E l ~ B o s q u e, ~ B o g o t a ́, ~ C o l o m b i a ~}$
}

"The authors of the above paper wish to acknowledge the help and advice of Dr C.M.C Volgenant, Department of Oral Health Sciences, ACTA, Amsterdam, The Netherlands. This Acknowledgement was omitted in error from the manuscript submitted to the Archives of Oral Biology.

The authors would like to apologise for any inconvenience caused."

\footnotetext{
DOI of original article: http://dx.doi.org/10.1016/j.archoralbio.2017.07.018

* Corresponding author at: Department of Oral Cell Biology, ACTA, Netherlands.

E-mail address: r.jalali@acta.nl (R. Jalali).
} 